\title{
Biological Control of Pierce's Disease of Grape by an Endophytic Bacterium
}

\author{
Clelia Baccari, Elena Antonova, and Steven Lindow ${ }^{\dagger}$
}

Department of Plant and Microbial Biology, University of California, Berkeley 94720.

Accepted for publication 24 October 2018.

\begin{abstract}
Effective preventive measures and therapies are lacking for control of Pierce's disease of grape caused by the xylem-colonizing bacterium Xylella fastidiosa responsible for serious losses in grape production. In this study we explored the potential for endophytic bacteria to alter the disease process. While most endophytic bacteria found within grape did not grow or multiply when inoculated into mature grape vines, Paraburkholderia phytofirmans strain PsJN achieved population sizes as large as $10^{6}$ cells $/ \mathrm{g}$ and moved $1 \mathrm{~m}$ or more within 4 weeks after inoculation into vines. While $X$. fastidiosa achieved large population sizes and moved extensively in grape when inoculated alone, few viable cells were recovered from plants in which it was co-inoculated with strain PsJN and the incidence of leaves exhibiting scorching symptoms typical of Pierce's disease was consistently greatly reduced from that in control plants. Suppression of disease symptoms occurred not only when strain PsJN was co-inoculated with the pathogen by puncturing stems in the same site in plants, but also when inoculated at the same time but at different sites in the plant. Large population sizes of strain PsJN could be

established in both leaf lamina and petioles by topical application of cell suspensions in $0.2 \%$ of an organo-silicon surfactant conferring low surface tension, and such treatments were as effective as direct puncture inoculations of this biocontrol strain in reducing disease severity. While inoculation of strain PsJN into plants by either method at the same time as or even 4 weeks after that of the pathogen resulted in large reductions in disease severity, much less disease control was conferred by inoculation of PsJN 4 weeks prior to that of the pathogen. The expression of grapevine PR1 and ETR1 within 3 weeks of inoculation was substantially higher in plants inoculated with both $X$. fastidiosa and strain PsJN compared with that in plants inoculated only with the pathogen or strain PsJN, suggesting that this biological control agent reduces disease by priming expression of innate disease resistance pathways in plants that otherwise would have exhibited minimal responses to the pathogen. Strain PsJN thus appears highly efficacious for the control of Pierce's disease when used as an eradicant treatment that can be easily made even by spray application.
\end{abstract}

Xylella fastidiosa is a xylem limited bacterium that is the cause of Pierce's disease of grapevine. It also causes disease on several other important crop plants, inciting citrus variegated chlorosis, coffee leaf scorch, almond leaf scorch, and similar type diseases on a wide variety of cultivated and native plants. Until recently, it was restricted largely to the Western Hemisphere but has recently been implicated in olive quick decline syndrome in Italy and found in a variety of locations in southern France and Spain (Chatterjee et al. 2008; Giampetruzzi et al. 2017; Saponari et al. 2017; Sicard et al. 2018). $X$. fastidiosa is obligately transmitted by various leafhopper vectors, notably various sharpshooter species in North and South America as well as the spittlebug Philaenus spumarius in Europe, being retained in the mouthparts of these xylem feeding insects (Saponari et al. 2014; Sicard et al. 2018). After inoculation into xylem vessels by leafhopper vectors, the pathogen moves extensively both laterally and longitudinally between xylem vessels, presumably via pits. Eventually a relatively large proportion of the xylem vessels harbor at least a few cells of the pathogen, with some vessels harboring large population sizes (Newman et al. 2003, 2004). Because of the time needed for extensive movement within the plant, disease is progressive, with symptoms developing only several weeks after inoculation. Most disease symptoms such as leaf scorching can be explained by the inability of the plant to transport water to upper parts of the plant as

${ }^{\dagger}$ Corresponding author: S. Lindow; E-mail: icelab@berkeley.edu

Funding: This work was supported by a grant from the Pierce's Disease and Glassy-Winged Sharpshooter Research Board, California Department of Food and Agriculture.

*The $\boldsymbol{e}$-Xtra logo stands for "electronic extra" and indicates that eight supplementary figures are published online.

(c) 2019 The American Phytopathological Society the incidence of vessel colonization by the pathogen increases. While some blockage of vessels by the pathogen may occur, it appears that the perception of the pathogen by the plant induces the formation of tyloses from adjacent xylem parenchymal cells that then block water movement, contributing to the restriction of water transport through the plant, leading to disease symptoms (Sun et al. 2013). Certain effector molecules such as lipases produced by $X$. fastidiosa may also contribute to disease symptoms (Nascimento et al. 2016).

As the extensive movement of $X$. fastidiosa through the plant is essential for both symptom development and successful transfer between plants by insect vectors, the pathogen has adapted a cell density-dependent transcriptional modulation system based on accumulation of fatty acids signal molecules known as diffusible signal factor (DSF) to coordinate expression of opposing traits required for growth and movement in the plant and those enabling acquisition by insect vectors, since the phenotypes required for these two processes are somewhat incompatible (Chatterjee et al. 2008; Ionescu et al. 2016). A novel disease control strategy aimed at achieving "pathogen confusion" based on production of DSF in transgenic plants harboring the pathogen DSF synthase yielded plants of much lower susceptibility to Pierce's disease (Lindow et al. 2014). Alternative strategies of producing DSF in plants that did not require the use of transgenic plant varieties and which could be employed in currently existing crops would be an attractive procedure. One such scheme could employ naturally occurring endophytic microorganisms into which the genes from $X$. fastidiosa encoding DSF synthesis could be added. A variety of endophytic bacteria recovered from surface-sterilized, field-grown grapes and other plant species have been described (Araujo et al. 2002; Azevedo et al. 2016; Bell et al. 1995; Lacava et al. 2004; Wilhelm and Kirkpatrick 2007). Most of these reports are rather qualitative, with the simple presence of a given taxon noted. Moreover, the population sizes of such bacteria within the aboveground parts of various woody plants were typically rather low $\left(<10^{3}\right.$ cells/g) 
(Hallmann et al. 1997). A relatively large and well distributed population of any such organism to be used in biological control would probably be needed. In contrast to the apparently low population sizes achieved by many bacteria that gain entrance into woody plants, Paraburkholderia phytofirmans PsJN (formerly known as Burkholderia phytofirmans and Pseudomonas sp. PsJN) (Mitter et al. 2013; Sawana et al. 2014; Sessitsch et al. 2005) has been reported to achieve large population sizes in plants, including grape (Compant et al. 2005, 2008). Nearly all studies of $P$. phytofirmans however have been qualitative studies of seedling plants, often inoculated via application to roots (Ledger et al. 2016; Miotto-Vilanova et al. 2016; Sharma and Nowak 1998; Su et al. 2016; Trda et al. 2014). We report here the extensive colonization of mature grapevines with strain PsJN, documenting its exceptional ability to grow and move within this woody plant. Furthermore, we report the unexpected results of the striking efficacy of $P$. phytofirmans PsJN itself, without addition of $X$. fastidiosa DSF synthase, in blocking colonization of grape by $X$. fastidiosa and dramatically reducing symptoms of Pierce's disease. Studies of the population dynamics of this strain as well as $X$. fastidiosa in coinoculated plants suggests a likely, DSF-independent, mechanism by which $P$. phytofirmans inhibits $X$. fastidiosa in plants and also reveals practical means by which plants can be inoculated with this biological control agent to achieve control of Pierce's disease.

\section{MATERIALS AND METHODS}

Bacterial strains. Wild-type $X$. fastidiosa subsp. fastidiosa strain Temecula (Newman et al. 2003) was used in most experiments. A spontaneous rifampicin resistant mutant of $P$. phytofirmans PsJN (Sessitsch et al. 2005) selected after streaking about $10^{8}$ cells on the surface of a plate of King's medium B (King et al. 1954) containing rifampicin (KBR) at $100 \mu \mathrm{g} / \mathrm{ml}$ was used in this study. In experiments in which $X$. fastidiosa populations were monitored in conjunction with those of strain PsJN, a gentamicin resistant, phoA mutant of X. fastidiosa Temecula (Beaulieu et al. 2013; Ionescu et al. 2013) having the same level of virulence as the wildtype strain was used. $X$. fastidiosa strains were grown on periwinkle Gelrite (PWG) media (Hill and Purcell 1995) or PWG containing gentamicin at $50 \mu \mathrm{g} / \mathrm{ml}$ as appropriate as well as natamycin at $100 \mu \mathrm{g} / \mathrm{ml}$. Strain PsJN was grown on KBR and natamycin at $100 \mu \mathrm{g} / \mathrm{ml}$. All strains were grown at $28^{\circ} \mathrm{C}$ and stored at $-80^{\circ} \mathrm{C}$ and recovered before each use.

Plant inoculations. All experiments were performed on greenhouse-grown self-rooted plants of Vitis vinifera 'Cabernet Sauvignon', 'Chardonnay', or 'Thompson Seedless' derived from segments of dormant vines. During winter months, supplemental light was provided. Plants were trained to have only one stem per plant. For mechanical inoculation of grapevine cuttings, a droplet puncture method in which $5-\mu 1$ drops of bacterial suspension was applied to the basal portion of stems when plants were approximately $40 \mathrm{~cm}$ tall and the droplet then punctured with an insect mounting needle as in other studies (Hill and Purcell 1995). When inoculated individually into a plant by droplet puncture, $5 \mu \mathrm{l}$ of a given bacterial strain having a concentration of $10^{8} \mathrm{cells} / \mathrm{ml}$ in $1 \mathrm{mM}$ potassium phosphate buffer, $\mathrm{pH} 7.0$, was applied. When $X$. fastidiosa and strain PsJN were co-inoculated at the same site into plants, $5 \mu \mathrm{l}$ of a mixed suspension of cells of each strain, each at a concentration of $10^{8}$ cells $/ \mathrm{ml}$, was introduced in buffer as above. In all experiments, $X$. fastidiosa strains were grown on PWG or PWG plates containing natamycin as appropriate for 5 days and strain PsJN was grown on KBR plates for 2 days before cells were harvested with a loop and suspended in phosphate buffer. The concentration of suspended cells was determined by measuring optical density $(\lambda=600 \mathrm{~nm})$ and diluted to a final concentration of $10^{8}$ cells $/ \mathrm{ml}$ with phosphate buffer. In some treatments strain PsJN was topically applied to the leaves of plants by spraying cell suspensions $\left(10^{8}\right.$ cells $\left./ \mathrm{ml}\right)$ in phosphate buffer containing $0.2 \%$ of the organo-silicon surfactant Breakthru (NewFarm Americas) using a hand-held sprayer that delivered a fine mist. The leaves were sprayed until wet, and cell suspensions began to drip from leaves (ca. $10 \mathrm{ml} / \mathrm{plant}$ ). A minimum of 10 plants were inoculated for each treatment.

Assessment of bacterial colonization of plants. The population size of either $X$. fastidios $a$ or strain PsJN was assessed within stems of plants that were sacrificed at various times after inoculation by excising $2 \mathrm{~cm}$ stem segments with a sterile razor blade either at the point of inoculation or at various distances distal to the point of inoculation. Stem segments were then surface sterilized by submersion for $2 \mathrm{~min}$ in $0.5 \%$ sodium hypochlorite followed by $2 \mathrm{~min}$ in $80 \%$ ethanol and then rinsed with 2 sterile water washes ( 2 min each). Surface-sterilized stem segments were then allowed to dry and an $8 \mathrm{~mm}$ segment was cut from the middle of the sample. The internal segment was placed in $2 \mathrm{ml}$ of buffer in small tubes and thoroughly macerated in a Pro200 polytron (Pro Scientific, Oxford, CT) for $30 \mathrm{~s}$. The entry of strain PsJN into leaf and petiole tissue after topical application with $0.2 \%$ Breakthru was assessed by similar methods; entire individual leaves were collected from plants at various times after spraying, surface sterilized with sodium hypochlorite and ethanol as above. Each petiole was then excised from the leaf with a sterile razor blade and macerated in $2 \mathrm{ml}$ buffer with a mortar and pestle. Each leaf or petiole was individually macerated in $10 \mathrm{ml}$ buffer in a mortar and pestle. The population sizes of $X$. fastidiosa or strain PsJN was determined by plating of appropriate dilutions of each macerated sample on PWG containing gentamicin at $100 \mu \mathrm{g} / \mathrm{ml}$ and/or KBR as appropriate and the number of colonies that arose after 10 days or 2 days incubation at $28^{\circ} \mathrm{C}$, respectively, were enumerated.

Assessment of disease severity. After inoculation, plants were grown in a greenhouse with minimum nighttime temperatures $>15^{\circ} \mathrm{C}$ and maximum daytime temperatures ranging from 20 to $32^{\circ} \mathrm{C}$ for up to 16 weeks. Beginning when any incidence of disease was apparent (after approximately 8 to 10 weeks) disease severity was repeatedly assessed (weekly) as the number of leaves on each inoculated vine exhibiting leaf scorching symptoms typical of Pierce's disease as before (Newman et al. 2003). The greenhouse plants used in these studies were very similar in size, and thus the number of leaves per vine was similar. In addition, since disease symptoms progress toward the distal end of inoculated vine from the point of inoculation, and the youngest, most distal leaves on a vine do not typically show any symptoms, measurements of the number of symptomatic leaves per vine also provides a direct assessment of the spatial movement of disease symptoms for the vine.

Measurement of DSF production. Possible DSF production in $P$. phytofirmans strain PsJN was assessed in culture extracts by the measurement of alkaline phosphatase activity exhibited by $X$. fastidiosa mutant strain MIX2* having a $r p f F^{*}$ genotype (E141A E161A) with a RpfF phenotype lacking ability to produce DSF but enabling it to participate in the perception of DSF together with $\mathrm{RpfC}$, harboring plasmid pXfHA encoding a promoterless $p h o A$ reporter gene fused to $X$. fastidiosa $h x f A$ as described previously (Beaulieu et al. 2013; Ionescu et al. 2013). Strain PsJN was grown in $\mathrm{KB}$ broth for 2 days to a cell concentration of $\mathrm{OD}_{600}$ of 1.5. Cells were removed by centrifugation $(6,000 \times \mathrm{g})$ for $10 \mathrm{~min}$ and $10 \mathrm{ml}$ of culture supernatant was partitioned into an equal volume of ethyl acetate which was then removed in vacuo and the precipitates resuspended in $100 \mu \mathrm{l}$ of water. The solute was then assessed for DSF activity by measuring alkaline phosphatase activity as before (Beaulieu et al. 2013).

Measurements of plant gene expression. Individual leaves from plants inoculated with buffer alone, X. fastidiosa, $P$. phytofirmans strain PsJN, and a mixture of $X$. fastidiosa and strain PsJN were collected a distal site near the point of inoculation $4 \mathrm{~h}$ after inoculation, and then weekly for up to 5 weeks. Petioles were immediately removed from each leaf and then pooled and 
instantly frozen in liquid nitrogen and stored at $-80^{\circ} \mathrm{C}$. For each sample, $100 \mathrm{mg}$ of tissue was ground to a powder in liquid nitrogen. Total RNA was isolated using ZR RNA Plant MiniPrep kit (Zymo Research) followed by DNase treatment with RNase-Free DNase set (Qiagen) according to the manufacturer's instructions. $300 \mathrm{ng}$ of total RNA was subjected to semiquantitative RT-PCR using the OneStep RT-PCR Kit (Qiagen) according to the manufacturer protocols. Primers used in the study included: PR1 (F: 5' GGAGTCCATTAGCACTCCTTTG-3'; R: 5'-CATAATTCTGGG CGTAGGCAG-3'), ETR1 (F: 5'-CAACTTTCCTACACTCTGC GTC-3'; R: 5'-TGGTACACGCACAGCAACAA-3'), Jaz1 (F: 5'CGTTCGTTTTCTGTACGCCTT-3'; R: 5'-TTGTTCCTCGCA CCTTCCTT-3'), and EF1 $\alpha$ (F: 5'-AACCAAAATATCCGGAG TAAAAGA-3'; R: 5'-GAACTGGGTGCTTGATAGGC-3'). PCR products were separated by conventional agarose gel electrophoresis $(1.5 \%)$.

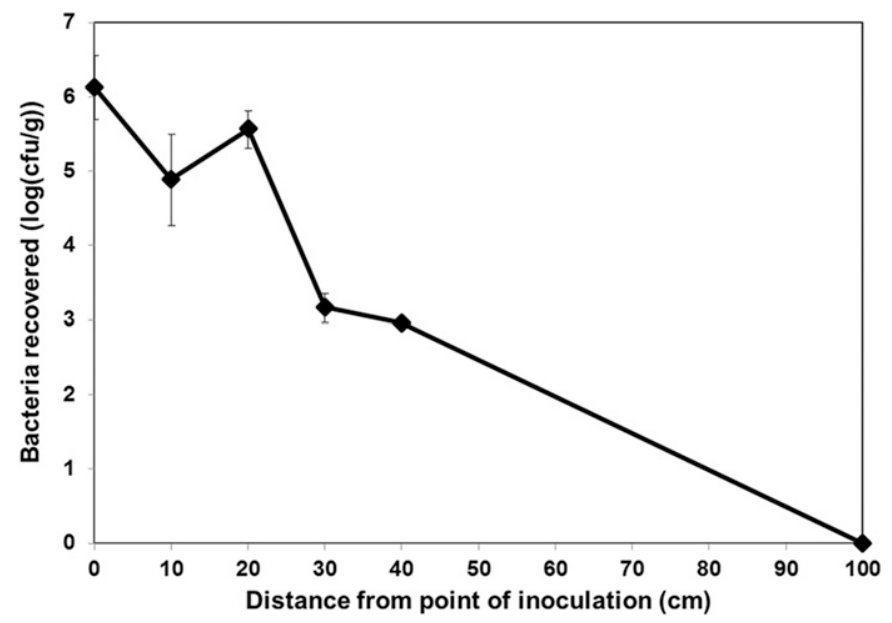

Fig. 1. Population size of Paraburkholderia phytofirmans PsJN in Cabernet Sauvignon grape stems at various distances from the point of inoculation after 6 weeks incubation. The vertical bars represent the standard error of mean logtransformed bacterial population sizes determined from samples collected from five plants.

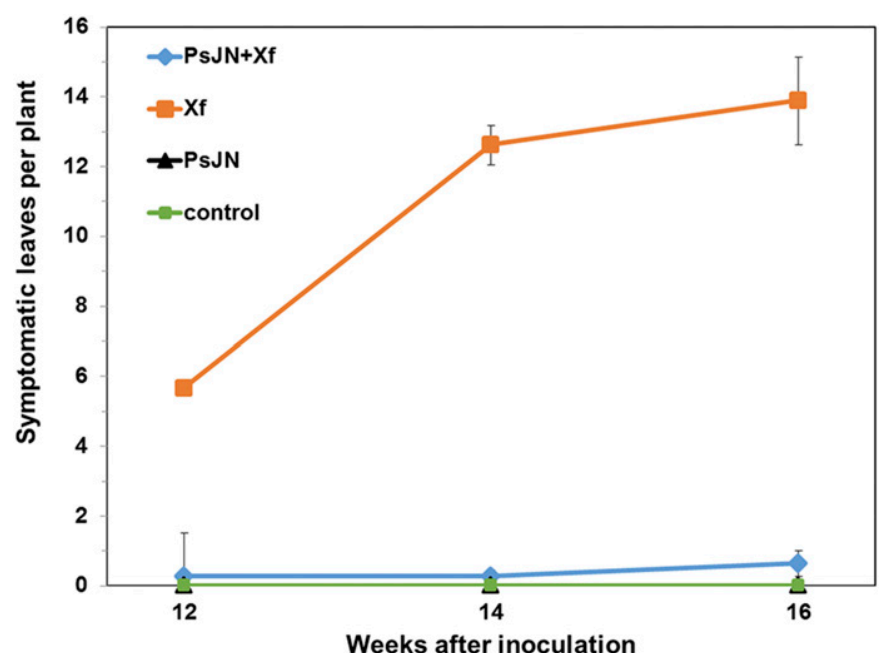

Fig. 2. Severity of Pierce's disease of Cabernet Sauvignon grape at various times after inoculation with Xylella fastidiosa alone (large squares) or when co-inoculated with Paraburkholderia phytofirmans PsJN (diamonds), when inoculated with $P$. phytofirmans PsJN alone (triangles), or in uninoculated plants (small squares). The vertical bars represent the standard error of the mean number of symptomatic leaves at a given assessment time from each of 12 plants receiving a given treatment.

\section{RESULTS}

Colonization of grape plants by endophytic bacteria. With the expectation that growth and/or movement of bacteria within the vascular tissue of mature grape would be required for successful biological control of Pierce's disease, we explored naturally occurring endophytic bacteria within grapes collected at various locations in Northern California for their ability to colonize mature grapes after reinoculation. While a diversity of bacterial taxa was recovered from a given surface-sterilized grape stem, the total population size was always low ( $<100$ cells/g) (data not shown). We measured the population size of each of several of these endophytic bacteria both at the point of inoculation and $15 \mathrm{~cm}$ away from the point of inoculation at various times after puncture inoculation into mature grape stems. While relatively small population sizes $\left(<10^{3}\right.$ $\mathrm{cfu} / \mathrm{g}$ ) of each of these bacteria could be recovered for 1 month or more after inoculation at the point of inoculation, population sizes did not increase with time, and few bacteria were detected $15 \mathrm{~cm}$ away from the point of inoculation after 4 weeks (data not shown). It thus appeared that none of the internalized bacteria found within field-grown grapes in California exhibited any net growth or movement when inoculated into mature grapes, and thus did not represent successful endophytes of this species, and therefore were not promising candidates for modulating the process of colonization of these plants by $X$. fastidiosa.

Unlike any of the bacteria recovered from surface-sterilized grape stems, large population sizes of $P$. phytofirmans PsJN, a strain isolated from onion (Sharma and Nowak 1998) and which had been shown to colonize the interior of various plant species (Compant et al. 2005, 2008) could be recovered both at the point of inoculation as well as at more distal locations after puncture inoculation of mature Cabernet Sauvignon grape when measured 6 weeks after inoculation. While over $10^{6}$ cells/g of stem tissue was recovered at the point of inoculation, population sizes were higher than about $10^{5}$ cells/g for as far as $20 \mathrm{~cm}$ away from the point of inoculation (Fig. 1). Furthermore, some cells of the strain could be detected as much as $40 \mathrm{~cm}$ away from the point of inoculation. No obvious alteration of the appearance of the plants was seen at any time after inoculation. It was thus clear that $P$. phytofirmans PsJN was a much more successful endophyte within mature grapes than any other strain tested.

Disease suppression in plants inoculated with $P$. phytofirmans PsJN. Because of the high endophytic fitness of $P$. phytofirmans PsJN within grape stems, the temporal progress of Pierce's disease was compared in plants in which $X$. fastidiosa was co-inoculated with an equal number of cells of strain PsJN with that in plants inoculated with the pathogen alone. As is typical for Pierce's disease, few leaf symptoms appeared in plants inoculated with the pathogen alone before 12 weeks after inoculation, but then increased rapidly with time (Fig. 2). Importantly, the severity of Pierce's disease was dramatically reduced in plants co-inoculated with the pathogen and strain PsJN; almost no leaves showed any evidence of Pierce's disease when assessed up to 16 weeks after coinoculation with strain PsJN. Disease severity was significantly lower on plants co-inoculated with $X$. fastidiosa and strain PsJN than on plants inoculated with the pathogen alone (Supplementary Fig. S1). Disease never became apparent in plants co-inoculated with the pathogen and strain PsJN even when maintained for longer periods of time in the greenhouse (data not shown).

Reduced colonization of plants by $X$. fastidiosa in the presence of $\boldsymbol{P}$. phytofirmans PsJN. The large reductions in the severity of disease when $X$. fastidiosa was co-inoculated with $P$. phytofirmans PsJN was associated with the apparent elimination of viable cells of the pathogen both at the point of inoculation as well as at various distances distal to the point of inoculation either 4 or 8 weeks after inoculation (Fig. 3). In contrast, the population size of $X$. fastidiosa increased progressively after its inoculation into grape in the absence of $P$. phytofirmans, reaching population sizes of 
approximately $10^{6}$ cells/g at all sites within about $60 \mathrm{~cm}$ from the point of inoculation, and moved to at least $120 \mathrm{~cm}$ from the point of inoculation within 8 weeks after inoculation (Fig. 3). Such large populations throughout the plant were associated with a high severity of disease, which increased between 11 and 14 weeks after inoculation (Fig. 4). In contrast, no viable cells of $X$. fastidios $a$ were detected at any location in these plants either 4 or 8 weeks after inoculation together with P. phytofirmans (Fig. 3) and no evidence of Pierce's disease was observed even by 14 weeks after inoculation (Fig. 4). The severity of Pierce's disease was significantly higher in plants inoculated only with the pathogen than on plants coinoculated with strain PsJN (Supplementary Fig. S2). By 4 weeks after inoculation, population sizes of $P$. phytofirmans of about $10^{4}$ cells/g were observed at all points up to $60 \mathrm{~cm}$ distal to the point of inoculation (Fig. 3). Curiously, while readily detected up to $90 \mathrm{~cm}$ or more from the point of inoculation when assessed 8 weeks after inoculation, $P$. phytofirmans population sizes were consistently about 10-fold lower at a given distance from the point of inoculation than at 4 weeks (Fig. 3). P. phytofirmans population sizes were often slightly lower at a given sampling time and location when coinoculated into plants with the pathogen compared with when it was inoculated alone (Fig. 3). Large reductions in population sizes of $X$. fastidiosa, often to undetectably low numbers, in plants inoculated with $P$. phytofirmans at various times, and in various ways, was always observed in the many experiments undertaken.

Biological control of Pierce's disease occurs in all grape cultivars tested. To determine the extent to which the large reduction in severity of Pierce's disease in plants inoculated with $P$. phytofirmans was context-dependent with respect to plant variety, the efficacy of biological control was compared in different grape varieties in which $X$. fastidiosa was co-inoculated with strain PsJN. As was seen in other experiments in which Cabernet Sauvignon grape was co-inoculated with the pathogen and $P$. phytofirmans, the severity of Pierce's disease at a given

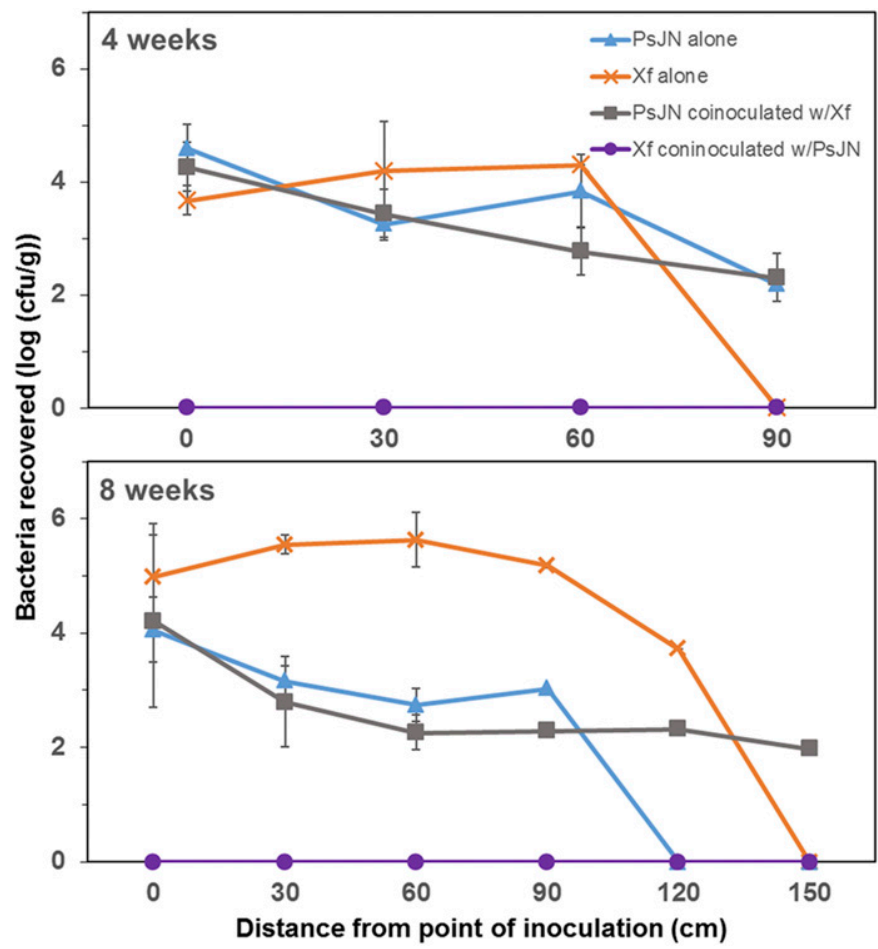

Fig. 3. Population size of Paraburkholderia phytofirmans PsJN in Cabernet Sauvignon grape stems when needle inoculated alone (triangles) or together with Xylella fastidiosa (squares), and X. fastidiosa when inoculated alone ( $\times$ symbol), or together with PsJN (circles) at various distances from the point of inoculation after 4 weeks incubation (top) or after 8 weeks incubation (bottom). The vertical bars represent the standard error of mean log-transformed bacterial population sizes determined from each of five replicate plants. assessment time after inoculation was greatly reduced compared with that of plants inoculated only with X. fastidiosa (Fig. 5). Importantly, co-inoculation of both Chardonnay and Thompson seedless grape with $X$. fastidiosa and $P$. phytofirmans also resulted in greatly reduced disease severity at a given time compared with that of plants inoculated with the pathogen alone (Fig. 5; Supplementary Fig. S3). It thus appears that the process of biological control of Pierce's disease with $P$. phytofirmans is not dependent on features present only in particular grape cultivars.

Spatial interactions of bacteria in biological control. To determine whether the inhibitory effects of $P$. phytofirmans on the process of Pierce's disease were dependent on any direct interactions between it and X. fastidiosa that might have occurred because of their mixture together at the point of inoculation, we compared the dynamics of disease process in plants in which the pathogen and strain PsJN were applied as mixed inoculum in the same site with that in plants in which they were inoculated separately up to $10 \mathrm{~cm}$ apart but at the same time. As previously observed, the severity of Pierce's disease in plants in which the pathogen and strain PsJN were applied as mixed inoculum in the same site in the plant was greatly reduced at a given time after inoculation compared with plants inoculated only with the pathogen (Fig. 6; Supplementary Fig. S4). Importantly, disease severity for plants inoculated at the same time but at different locations with these two strains was usually nearly as low as that in plants receiving a mixed inoculum. Both treatment schemes resulted in very large reductions in disease severity compared with that of control plants inoculated only with the pathogen (Fig. 6).

Spray inoculation of $\boldsymbol{P}$. phytofirmans PsJN. Given that close physical proximity of $X$. fastidiosa and P. phytofirmans at the time of inoculation of the pathogen is apparently not required to achieve large reductions in disease, we explored methods of inoculation of plants with strain PsJN that might ultimately prove more practical for implementation under field conditions than injection into stems. Spray application of bacterial inoculum might readily be adoptable by growers because of similarities in methodology and equipment used in other pest management procedures. Topical application of suspensions of $P$. phytofirmans of $10^{8}$ cells $/ \mathrm{ml}$ in buffer alone resulted in only very low internalized population sizes of this strain within either petioles or leaf lamina

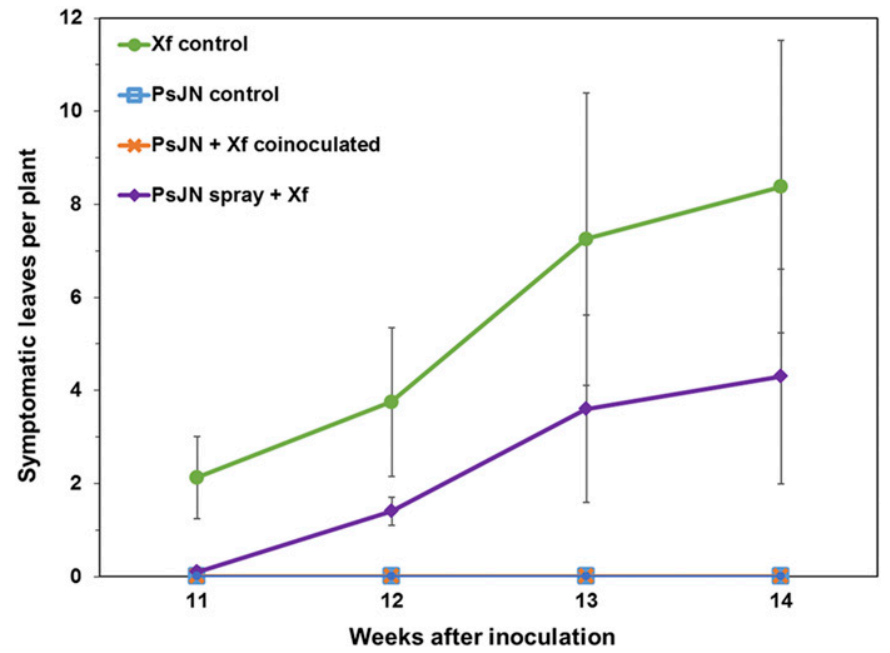

Fig. 4. Severity of Pierce's disease symptoms on Cabernet Sauvignon grape in the experiment also described in Figure 3 that were inoculated only with Xylella fastidiosa (circles), needle inoculated with a mixture of $X$. fastidiosa and Paraburkholderia phytofirmans PsJN ( $\times$ symbol), inoculated with $X$. fastidiosa immediately after spray inoculation of PsJN in $0.2 \%$ Breakthru (diamonds), or needle inoculated only with PsJN (squares). The vertical bars represent the standard error of the mean number of symptomatic leaves at a given assessment time from each of 10 replicate plants for each treatment. 
when assessed at different times after spray application (Fig. 7). In contrast, the population size of strain PsJN applied in buffer containing $0.2 \%$ Breakthru, an organo-silicon surfactant conferring extremely low surface tension to aqueous solutions, (similar to that of Silwet L77), were about 1000-fold higher than that within leaves sprayed with bacterial suspensions in buffer alone (Fig. 7). Furthermore, the population size of strain PsJN was about 100-fold higher within the lamina of the leaf compared with that within the petioles. Not only were large internalized populations of $P$. phytofirmans achieved immediately after inoculation $\left(>10^{3}\right.$ to $10^{5}$ cells/g), but these endophytic bacterial population sizes increased with time for at least 9 days after spray inoculation (Fig. 7). In many other experiments in which strain PsJN was topically applied with $0.2 \%$ Breakthru the population size of strain PsJN within leaves immediately after inoculation was as high as $10^{5}$ cells/g (data not shown). The leaves sprayed with bacterial suspensions containing this surfactant immediately acquired a water-soaked appearance, indicative of water infiltration into the leaf (Supplementary Fig. S5). The number of bacteria introduced into the plant by such sprays appeared to be influenced by the water

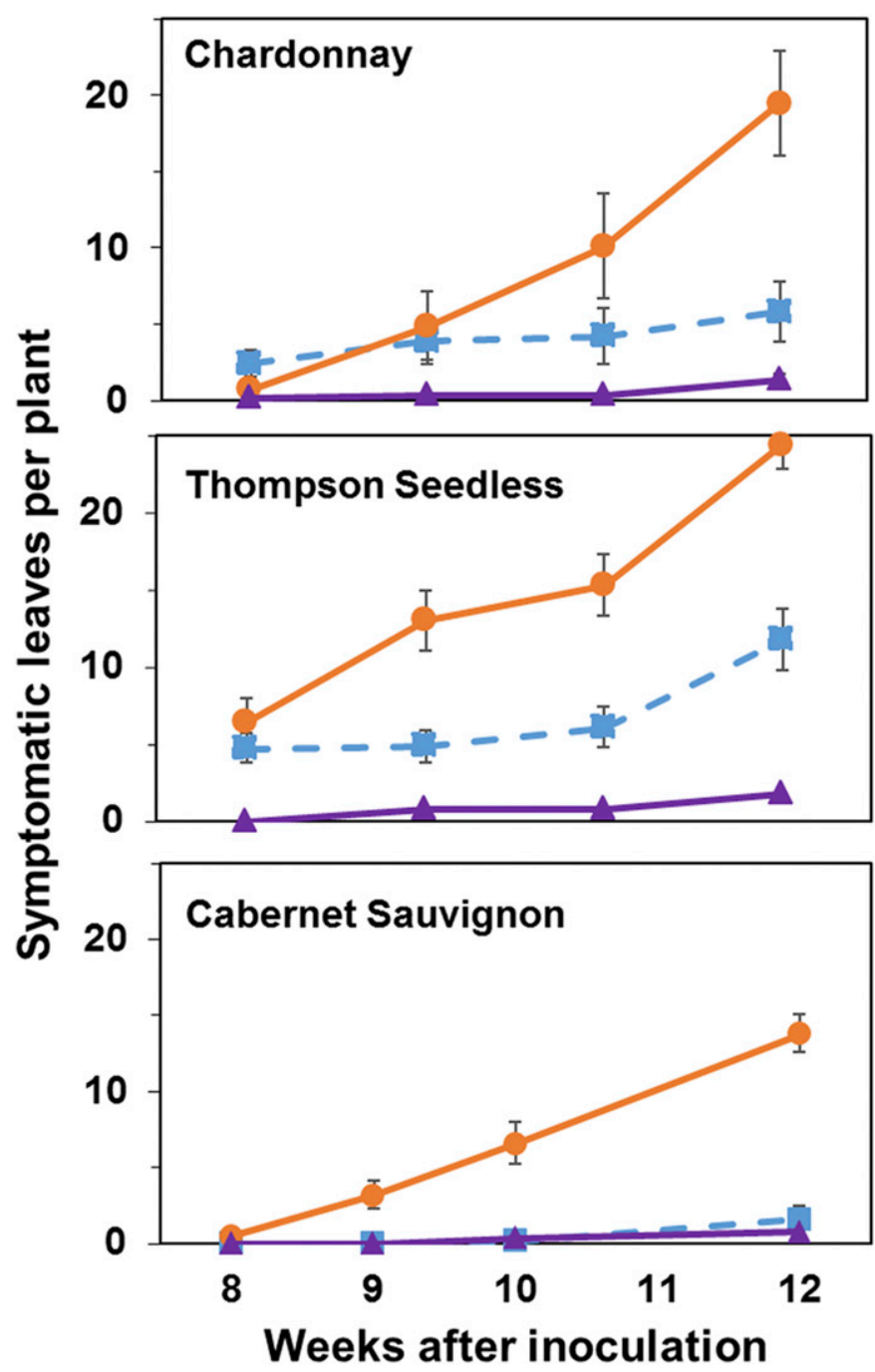

Fig. 5. Severity of Pierce's disease observed in different grape varieties needle inoculated within $10 \mathrm{~min}$ at nearby locations at the base of plants with Xylella fastidiosa and Paraburkholderia phytofirmans PsJN (squares) compared with that inoculated only with $X$. fastidiosa (circles), or with B. phytofirmans alone (triangles). The vertical bars represent the standard error of the determination mean disease severity for 15 plants co-inoculated with $X$. fastidiosa and strain PsJN, 10 plants inoculated with the pathogen alone, and 5 uninoculated control plants when assessed at a given time. status of the plant and whether stomata were fully open, both of which influenced the degree of water infiltration. It thus appears that $P$. phytofirmans can be readily inoculated into grape by simple spray application when appropriate surfactants are used.

The severity of Pierce's disease on plants sprayed with $P$. phytofirmans immediately before inoculation with $X$. fastidiosa was significantly lower than on control plants inoculated with the pathogen alone (Figs. 4 and 6; Supplementary Fig. S6 and S7). While disease severity of plants sprayed with $P$. phytofirmans at the same time as inoculation with the pathogen was often slightly higher than that on plants that were puncture-inoculated with this strain as the pathogen when assessed at a given time, the severity of disease severity in both treatments were always significantly less than that of control plants inoculated only with the pathogen, and often did not differ significantly. It appears that topical application of $P$. phytofirmans with a surfactant that allows spontaneous stomatal infiltration is nearly as effective in mediating control of Pierce's disease as direct inoculation of this biological control agent into xylem tissue.

Temporal bacterial interactions in biological control. While X. fastidiosa and $P$. phytofirmans apparently do not need to be entirely spatially coincident at the time of inoculation of the pathogen in order to achieve suppression of Pierce's disease symptoms, and substantial disease control was inevitably obtained when the two strains were inoculated at the same time into plants by various ways, insights as to the possible mechanisms contributing to disease control were obtained by inoculating strain PsJN into plants at various times relative to that of the pathogen. Surprisingly, the extent to which the severity of Pierce's disease was reduced when $P$. phytofirmans was inoculated into plants either by injection or spray application 4 weeks prior to inoculation with $X$. fastidiosa was invariably less than when the two strains were applied at the same time when made by the same method of PsJN application. For example, in some experiments, Pierce's disease severity in plants

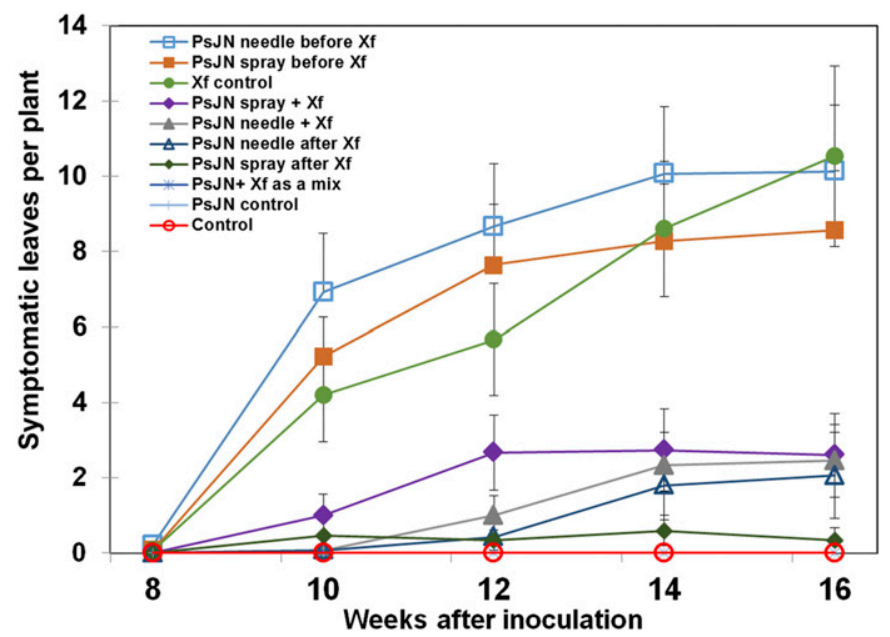

Fig. 6. Severity of Pierce's disease symptoms on Cabernet Sauvignon grape inoculated only with Xylella fastidiosa (filled circles), needle inoculated with a mixture of $X$. fastidiosa and Paraburkholderia phytofirmans PsJN at the same site $(\times$ symbol), needle inoculated at the same time with $X$. fastidios $a$ and $P$. phytofirmans PsJN but at different sites on the base of the plant (filled triangles), inoculated with $X$. fastidiosa immediately after spray inoculation of PsJN in $0.2 \%$ Breakthru (filled diamonds), needle inoculated with PsJN 30 days before inoculation with $X$. fastidiosa (open squares), sprayed with PsJN in $0.2 \%$ Breakthru 30 days before inoculation with $X$. fastidiosa (filled squares), sprayed with PsJN in $0.2 \%$ Breakthru 30 days after inoculation with $X$. fastidiosa (filled diamonds), needle inoculated with PsJN 30 days after inoculation with $X$. fastidiosa (open triangles), needle inoculated only with PsJN (vertical slash), or on uninoculated plants (open circles). The vertical bars represent the standard error of the mean number of symptomatic leaves assessed on each of 15 replicate plants for each treatment at a given assessment time. 
treated with $P$. phytofirmans either by needle inoculation or spraying 4 weeks before that of the pathogen did not differ from that of plants inoculated with the pathogen alone, while simultaneous inoculation with strain PsJN by either method conferred very large reductions in disease severity compared with control plants (Fig. 6). In other experiments, pretreatments of plants with $P$. phytofirmans either by needle inoculation or spraying conferred significant reductions in disease severity compared with that of control plants, yet the extent of disease control was substantially less than that conferred by corresponding needle or spray inoculation at the same time as the pathogen. Disease severity in plants sprayed with $P$. phytofirmans was however consistently less than that in plants to which strain PsJN had been inoculated by puncturing before the pathogen (Fig. 6). Even more surprising however was the observation that disease control achieved by puncture or spray inoculation of $P$. phytofirmans into plants 3 to 4 weeks after inoculation of the pathogen was as great as, and often greater than, that achieved by simultaneous inoculation by a given method (Fig. 6). Given that population sizes of $X$. fastidiosa typically increase and spread extensively in inoculated plants within 4 weeks (Fig. 3), it was remarkable to find, as in other experiments, very low or undetectable population sizes of $X$. fastidiosa subsequent to such treatments with $P$. phytofirmans, even though it was applied 4 weeks after that of the pathogen (data not shown).

Insight as to the surprising observation that pretreatment of plants with $P$. phytofirmans inevitably reduced its efficacy in biological control of Pierce's disease compared with simultaneous or postinoculation treatments was provided by analysis of the temporal patterns of colonization of plants by strain PsJN. We frequently observed that while relatively large population sizes of $P$. phytofirmans could be detected throughout grape within a few weeks after inoculation, this population size often subsequently decreased, often dramatically so (Fig. 3; data not shown). A more systematic examination of $P$. phytofirmans populations when coinoculated with $X$. fastidiosa in grape as a function of time revealed that its population size and distribution distal to the point of inoculation both increased for at least 3 weeks after inoculation, but then started to decrease by 5 weeks (Supplementary Fig. S8). As in most other experiments, viable cells of $P$. phytofirmans often became undetectably low within 10 weeks after inoculation (data not shown). As in all experiments, when inoculated in the absence of $P$. phytofirmans both the population size and extent of distribution

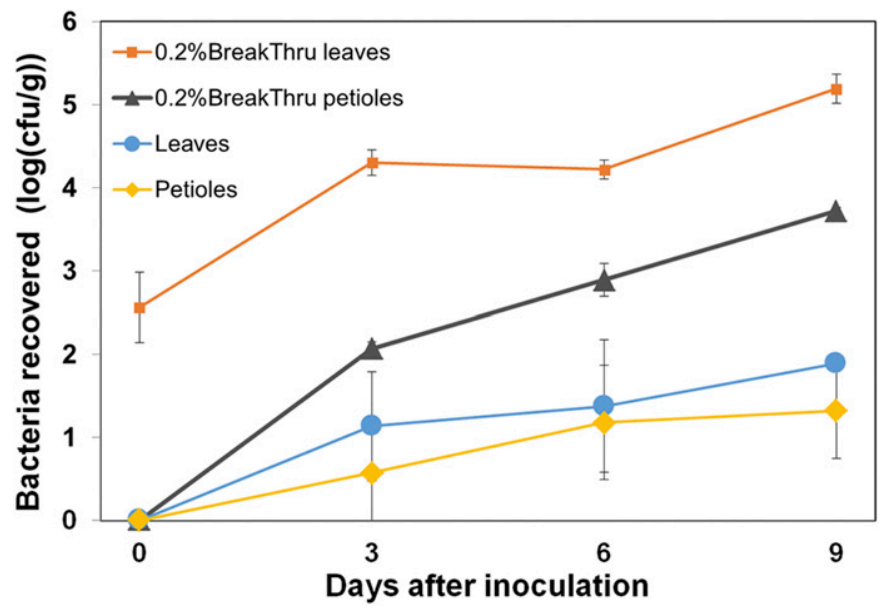

Fig. 7. Population size of Paraburkholderia phytofirmans PsJN within leaves (squares) or petioles (triangles) when sprayed onto Cabernet Sauvignon grape with $0.2 \%$ Breakthru or within leaves (circles) or petioles (diamonds) when sprayed onto plants in buffer alone, when sampled at various times after inoculation shown on the abscissa. The vertical bars represent the standard error of the mean of long-transformed population sizes determined on each of five replicate plants for each treatment when sampled at a given time after inoculation. of $X$. fastidiosa distal to the point of inoculation tended to increase with time while viable cells of the pathogen were not detected at any time or distance from the point of inoculation when co-inoculated with strain PsJN.

Induced host defenses. The findings that $X$. fastidiosa populations usually became undetectably low in plants harboring P. phytofirmans, even if the biological control agent was applied to plants after that of the pathogen, suggested that direct effects of $P$. phytofirmans were not responsible for the inhibition of the pathogen. Instead, a process wherein $P$. phytofirmans was inducing plant resistance to $X$. fastidiosa seemed more likely to account for the suppression of disease. To test this hypothesis, we examined the expression of various genes in grape that are responsible for, or reflective of, responses to pathogens, mechanical, and abiotic stresses. The abundance of PR1 indicative of induction of salicylic acid-mediated host defenses, JAZ1 indicative of jasmonic acidmediated host defenses, and ETR1 reflecting ethylene-dependent responses were determined in RNA isolated from petioles collected from near the point of inoculation of plants by semiquantitative RT-PCR. The abundance of EF1a, expected to be constitutively expressed, was used as an internal control to account for the efficiency of RNA isolation. The abundance of these indicator transcripts was compared in plants inoculated only with $P$. phytofirmans, $X$. fastidiosa, or co-inoculated with the pathogen and strain PsJN weekly after inoculation as well as in mock-inoculated plants. Little expression of JAZ1 was detected in any of the plants, irrespective of the sampling time after inoculation (Fig. 8). In contrast, some PR1 transcript was seen soon after inoculation of plants only with $P$. phytofirmans, with lesser amounts subsequently detected. Low levels of PR1 transcript were also observed within 1 week of inoculation of plants only with $X$. fastidiosa, with reductions thereafter. Most notably, the highest levels of PR1 transcript were observed in plants co-inoculated with $P$. phytofirmans and $X$. fastidiosa, with the apparent abundance of this transcript increasing with time up to 3 weeks (Fig. 8). The abundance of PR1 transcript in these plants decreased rapidly thereafter (data not

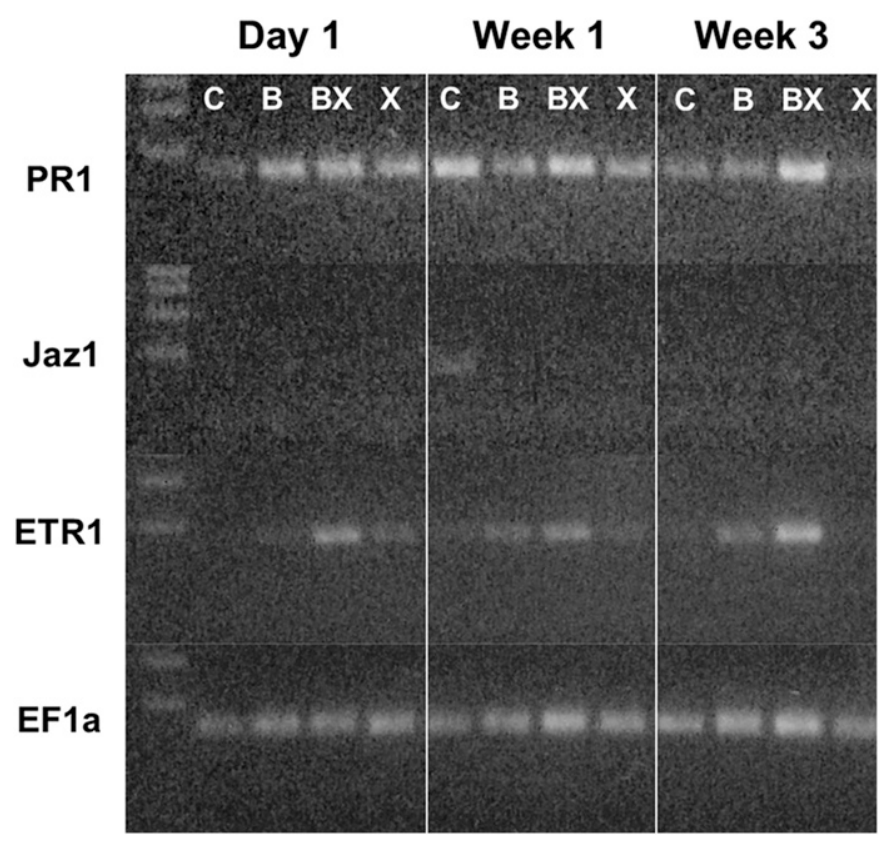

Fig. 8. Products obtained after PCR amplification of cDNA obtained from RNA that had been subjected to reverse transcription that was isolated from petioles of Cabernet Sauvignon grape near the point of inoculation of plants that were inoculated only with buffer (C), inoculated with Paraburkholderia phytofirmans PsJN alone (B), inoculated with both PsJN and Xylella fastidiosa (BX), or were inoculated with X. fastidiosa alone (X). Bands corresponding to amplification products of PR1, Jaz1, ETR1, and EF1a from RNA sampled from plants harvested at the various times shown above each lane. 
shown). Very low levels of ETR1 transcript were observed in all plants except those co-inoculated with $P$. phytofirmans and $X$. fastidiosa (Fig. 8). This suggests that an interaction between $P$. phytofirmans and $X$. fastidiosa induces both the SA- and ethylenedependent signal transduction pathways in grape to levels higher than that mediated by either strain alone.

\section{DISCUSSION}

The observations of the biological control of Pierce's disease by $P$. phytofirmans PsJN made here are consistent with a model in which this strain readily, but transiently, colonized the xylem vessels of grape, thereby priming the plant to mount an induced systemic response (ISR) to the pathogen. Such defense priming has been previously studied primarily in the context of resistance to foliar pathogens (Pieterse et al. 2014). Although the terms ISR and systemic acquired resistance (SAR) are often considered to be synonymous, SAR commonly refers to the situations in which resistance is induced by a pathogen and is dependent on SA pathways. In contrast, ISR is typically induced by beneficial microorganisms and the plant responses are often SA independent (Pieterse et al. 2014). Nearly all studies of ISR have been of beneficial rhizobacteria whose initial, and most extensive, interactions with plants occur in and on roots. Some rhizobacteria such as strain PsJN can colonize more distal parts of the plants as well (Compant et al. 2008; Sessitsch et al. 2005). P. phytofirmans PsJN is considered a beneficial bacterium and has been studied previously almost exclusively in studies in which it has been applied in high numbers to roots of seedling plants that are often grown in somewhat in vitro conditions (Ledger et al. 2016; Miotto-Vilanova et al. 2016; Sharma and Nowak 1998; Su et al. 2016; Trda et al. 2014). Several studies have shown that treatment of the roots of various plant species such as Arabidopsis and grape subsequently result in detectable populations of this strain in the foliar parts of the plant, and even in flowers and seeds (Compant et al. 2008). Many different phenotypic changes have been observed in plants whose roots have been inoculated with PsJN. For example, metabolomics changes associated with cold and other abiotic stresses have been noted (Fernandez et al. 2012; Su et al. 2016; Theocharis et al. 2012). Like many plant growth-promoting rhizobacteria, inoculation of seedlings with strain PsJN can result in increased plant growth (Compant et al. 2005; Ledger et al. 2016; Mitter et al. 2013; Pillay and Nowak 1997; Sessitsch et al. 2005). Importantly, resistance to both Pseudomonas syringae infection of Arabidopsis and Botrytis cinerea infection of grape following root inoculation have been reported (Miotto-Vilanova et al. 2016; Timmermann et al. 2017). The increased resistance of grape to Botrytis infection was associated with a stronger expression of PR1 and JAZ genes only in the presence of both PSJN and the pathogen, suggesting that resistance to the pathogen was being primed. Likewise, SA, JA, and ethylene signaling pathways were apparently activated in Arabidopsis whose roots were pretreated with strain PsJN before that of Pseudomonas syringae. Unlike these foliar pathogens, $X$. fastidiosa is strictly xylem limited, and presumably any immune response to such a pathogen would be restricted to that of the living parenchymal cells surrounding xylem tissue (Rapicavoli et al. 2018). It is apparent that plants such as grape can perceive the presence of $X$. fastidiosa since higher ethylene production is observed in $X$. fastidiosa-infected vines than in healthy vines. Elevated ethylene, in turn, is linked to a signaling process that initiates the formation of tyloses that contribute to symptoms of Pierce's disease by blocking water movement through the plant (Perez-Donoso et al. 2007). A recent important study has revealed that SA-dependent disease defense pathways in grape are not normally induced during infection with $X$. fastidiosa (Rapicavoli et al. 2018). However, SA-dependent defenses were induced both by an $\mathrm{O}$-antigen deficient mutant of $X$. fastidiosa and purified lipopolysaccharide (LPS), and these plants were also highly resistant to infection by the wild type pathogen (Rapicavoli et al. 2018). These observations are strongly supportive of a model in which $X$. fastidiosa is a successful pathogen of plants such as grape because plant defenses are not activated because of the camouflaging of its LPS by the O-antigen, but that a robust SAR is possible if appropriate perception of microbial associated molecular patterns are perceived by living cells adjacent to the xylem. It is thus clear that a primed state of disease resistance can be induced by treating grapevines with appropriate elicitors such as LPS. We propose that $P$. phytofirmans PsJN is perceived in mature grape xylem, thereby priming plant resistance to $X$. fastidiosa. Support for this model is provided by the observation that PR 1 abundance was higher in plants co-inoculated with both strain PsJN and the pathogen compared with that in plants inoculated only with the pathogen (Fig. 8). As was previously observed (Rapicavoli et al. 2018), little expression of PR1 was noted in plants inoculated with the pathogen alone (Fig. 8). It is noteworthy however that some elevation of PR1 expression was observed for about 3 weeks in plants inoculated with strain PsJN alone, although substantially less than that in plants also inoculated with the pathogen (Fig. 8). Given that the population size of PsJN increased rapidly for about 3 weeks after inoculation but then decreased thereafter (Fig. 3) it is tempting to speculate that this strain was itself being perceived by the plant and progressively induced a resistance response as it grew, causing a subsequent crash in its population size. It would appear however, that the response of grape to $P$. phytofirmans itself is less robust than to the pathogen when primed by the presence of PsJN. P. phytofirmans may also be somewhat more tolerant of the plant responses than the pathogen. Strong support for this later conjecture is provided by the observations in Figure 3 which reveals a modest decline in the population size of $P$. phytofirmans over time in co-inoculated plants while $X$. fastidiosa becomes unrecoverable at all times. That the population size of $P$. phytofirmans was generally lower in plants coinoculated with the pathogen than when alone (Fig. 3) is consistent with the finding that the primed immune response to the pathogen is somewhat stronger than the response to PsJN alone (Fig. 8). In this model, P. phytofirmans, having traits that allow it to readily multiply and move throughout the xylem of grape, soon becomes selflimiting due to its own success in grape, apparently by inducing plant defenses. Since killed cells of PsJN were found to be incapable of inducing ISR in Arabidopsis (Timmermann et al. 2017) we propose that priming of resistance to $X$. fastidiosa by the strain would be relatively short-lived, as the plant response to PsJN, and particularly its response to the presence of both bacteria in the xylem, would tend to dampen any subsequent priming. Indeed, both ISR and SAR have been shown to be short-lived phenomenon in other plant systems (Pieterse et al. 2014). Such a scenario could readily account for the patterns of disease control observed here when $P$. phytofirmans was inoculated into grape at various times relative to that of the pathogen. The low levels of disease protection conferred by inoculation of strain PsJN several weeks prior to the pathogen could reflect diminution of the priming effect as PsJN population sizes plummet. On the other hand, given that disease development incited by $X$. fastidiosa is slow, $P$. phytofirmans could exhibit rapid multiplication in asymptomatic plants already infected with the pathogen, thereby inducing a strong priming effect, causing elimination of the pathogen, and presumably itself as collateral damage.

Several observations made here suggested that the suppression of disease in plants inoculated with $P$. phytofirmans strain PsJN was not associated with any production of DSF. Disease control is apparently associated with mechanisms other than that of pathogen confusion resulting from the production of DSF. Firstly, while substantial reductions of Pierce's disease symptoms were observed in DSF-producing transgenic plants both in greenhouse and field studies, disease symptoms were usually seen in leaves close to the point of inoculation, since DSF production merely slowed the movement of $X$. fastidiosa through the plant (Lindow et al. 2014). In 
contrast, leaves exhibiting scorching typical of Pierce's disease were almost never seen, even close to the point of pathogen inoculation in plants co-inoculated with strain PsJN (Fig. 2). Secondly, no evidence was obtained for the production of extracellular products by strain PsJN that could serve as DSF-like signal molecule. Specifically, cells of an X. fastidiosa rpfF* mutant incapable of producing DSF but capable of perceiving DSF and harboring an $h x f A: p h o A$ reporter gene fusion did not increase in its production of alkaline phosphatase even in the presence of concentrated extracts of cell-free supernatants of $P$. phytofirmans PsJN (data not shown). While many Burkholderia strains can produce one or more cis-2 unsaturated fatty acids that serve as DSFlike quorum sensing molecules, strain PsJN apparently does not (Suppiger et al. 2016). These results indicate that the quorum sensing system of $X$. fastidiosa was not responsive to extracellular products of $P$. phytofirmans and support the observation that strain PsJN did not produce any DSF-like molecules detectable using another DSF reporter gene system in Burkholderia cepacia (Suppiger et al. 2016). Thirdly, unlike the suppression of Pierce's disease symptoms in transgenic DSF-producing grape plants the large reductions in the severity of disease when $X$. fastidiosa was coinoculated with $P$. phytofirmans PsJN was associated with the apparent elimination of most viable cells of the pathogen. Viable cells of the pathogen could not be detected either at the point of inoculation or at various distances distal to the point of inoculation either 4 or $8 \mathrm{~h}$ after inoculation (Fig. 3). Such apparent elimination of the pathogen from the plant in the presence of strain PsJN is quite distinct from that observed in DSF-producing plants in which the multiplication and the spatial distribution of $X$. fastidiosa was only reduced while viable cells of the pathogen could still be readily recovered (Lindow et al. 2014).

There is circumstantial evidence that other endophytic bacteria found within plants are not as efficacious as $P$. phytofirmans in suppressing the multiplication of $X$. fastidiosa. Nearly all studies of endophytic bacteria in grapes, citrus, and other plants find that bacteria recoverable from within surface-sterilized plants are almost always in much lower population sizes than that seen here after inoculation of $P$. phytofirmans PsJN into stems of mature grape. The population size of PsJN that developed within grape was also much higher than in other studies in which large numbers of potential endophytes were applied to roots of various plant species. For example, the population size of taxa such as Methylobacterium mesophilicum commonly occur together with $X$. fastidiosa in citrus tissues but only at population sizes of less than about $10^{3}$ cells/g (Azevedo et al. 2016). Certain other taxa are also occasionally seen within infected citrus, but often at a low proportion of samples (Araujo et al. 2002). While fungi such as Cochliobolus sp. that produce radicinin that is toxic to $X$. fastidiosa have been recovered from plants that have escaped Pierce's disease in the field, studies have not yet reported whether such strains represent an effective means of preventing infection (Aldrich et al. 2015). Co-inoculation of Curtobacterium flacumfaciens modestly reduced disease symptoms in Catharanthus roseus when inoculated with $X$. fastidiosa, but the study provided no insight into the mechanism by which this effect had occurred (Lacava et al. 2004, 2007). Likewise, certain strains of $X$. fastidiosa that are apparently only weakly pathogenic to grape conferred some level of biological control of Pierce's disease when inoculated prior to virulent pathogens, although the nature of the interaction remains elusive (Hopkins 2005). While these negative associations of various endophytes with disease have been observed, the ability of $P$. phytofirmans to strongly suppress $X$. fastidiosa in grape suggests that this interaction is distinct from, and of a greater magnitude, than that seen in other associations.

Several features of the interactions observed here between $P$. phytofirmans and $X$. fastidiosa suggest that such a strain might be readily amenable for practical implementation of Pierce's disease control. Many, if not most biological control agents work best in a prophylactic mode since they often must multiply to sufficiently large population sizes to compete for resources, produce inhibitory compounds, or induce resistance before infection occurs. However, not only was co-inoculation of $P$. phytofirmans with the pathogen a very effective means of preventing disease symptoms, but remarkably, inoculation after infection with the pathogen was even more effective. Given that colonization of grapes by P. phytofirmans is apparently self-limiting, it remains unclear how long the benefit of its inoculation into plants may persist. While its inoculation alone seems to provide little protection beyond 3 to 4 weeks, inoculation at the time of infection with the pathogen might prime plants for longer period although measures of defense-related genes suggest a diminishing priming effect (Fig. 8) as expected from other studies of ISR and SAR (Pieterse et al. 2014). Since treatment with $P$. phytofirmans appears to nearly eradicate the pathogen after infection, one might not need to anticipate disease and instead it may be possible to periodically apply such a strain after infection has occurred, but before symptom development. Such a strategy may require repeated treatments with strain PsJN since infections can occur throughout a growing season if infectious vectors are active. Spray application of $P$. phytofirmans appears to be a particularly attractive treatment strategy. Direct introduction of P. phytofirmans into leaves may maximize its ability to interact with living plant cells, thereby accounting for the high efficacy of this treatment method. Since several commercially available organosilicon surfactants are registered for use at the high concentrations needed for the spontaneous stomatal infiltration of $P$. phytofirmans, commercialization of such a disease control strategy might be readily achieved.

\section{ACKNOWLEDGMENTS}

We thank R. Koutsoukis for assistance with many of the experiments and for help in preparing the figures and $\mathrm{C}$. Wistrom and others at the Oxford facilities unit for their help in propagating plants. We appreciate the donation of dormant virus-free plant material used in these studies by Foundation Plant Services, University of California, Davis.

\section{LITERATURE CITED}

Aldrich, T. J., Rolshausen, P. E., Roper, M. C., Reader, J. M., Steinhaus, M. J., Rapicavoli, J., Vosburg, D. A., and Maloney, K. N. 2015. Radicinin from Cochliobolus sp. inhibits Xylella fastidiosa, the causal agent of Pierce's disease of grapevine. Phytochemistry Amst. 116:130-137.

Araujo, W. L., Marcon, J., Maccheroni, W., van Elsas, J. D., van Vuurde, J. W. L., and Azevedo, J. L. 2002. Diversity of endophytic bacterial populations and their interaction with Xylella fastidiosa. Appl. Environ. Microbiol. 68:4906-4914.

Azevedo, J. L., Araujo, W. L., and Lacava, P. T. 2016. The diversity of citrus endophytic bacteria and their interactions with Xylella fastidiosa and host plants. Genet. Mol. Biol. 39:476-491.

Beaulieu, E. D., Ionescu, M., Chatterjee, S., Yokota, K., Trauner, D., and Lindow, S. 2013. Characterization of a diffusible signaling factor from Xylella fastidiosa. MBio 4:e00539.

Bell, C. R., Dickie, G. A., Harvey, W. L. G., and Chan, J. W. Y. F. 1995. Endophytic bacteria in grapevine. Can. J. Microbiol. 41:46-53.

Chatterjee, S., Almeida, R. P. P., and Lindow, S. 2008. Living in two worlds: The plant and insect lifestyles of Xylella fastidiosa. Annu. Rev. Phytopathol. 46:243-271.

Compant, S., Kaplan, H., Sessitsch, A., Nowak, J., Barka, E. A., and Clement, C. 2008. Endophytic colonization of Vitis vinifera L. by Burkholderia phytofirmans strain PSJN: From the rhizosphere to inflorescence tissues. FEMS Microbiol. Ecol. 63:84-93.

Compant, S., Reiter, B., Sessitsch, A., Nowak, J., Clement, C., and Barka, E. A. 2005. Endophytic colonization of Vitis vinifera L. by plant growth promoting bacterium Burkholderia sp. strain PsJN. Appl. Environ. Microbiol. 71:1685-1693.

Fernandez, O., Theocharis, A., Bordiec, S., Feil, R., Jacquens, L., Clement, C., Fontaine, F., and Barka, E. A. 2012. Burkholderia phytofirmans PsJN acclimates grapevine to cold by modulating carbohydrate metabolism. Mol. Plant-Microbe Interact. 25:496-504.

Giampetruzzi, A., Saponari, M., Loconsole, G., Boscia, D., Savino, V. N., Almeida, R. P. P., Zicca, S., Landa, B. B., Chacon-Diaz, C., and Saldarelli, P. 2017. Genome-wide analysis provides evidence on the genetic 
relatedness of the emergent Xylella fastidiosa genotype in Italy to isolates from Central America. Phytopathology 107:816-827.

Hallmann, J., Quadt-Hallmann, A., Mahaffee, W. F., and Kloepper, J. W. 1997. Bacterial endophytes in agricultural crops. Can. J. Microbiol. 43:895-914.

Hill, B. L., and Purcell, A. H. 1995. Multiplication and movement of Xylella fastidiosa within grapevine and four other plants. Phytopathology 85: 1368-1372.

Hopkins, D. L. 2005. Biological control of Pierce's disease in the vineyard with strains of Xylella fastidiosa benign to grapevine. Plant Dis. 89: 1348-1352.

Ionescu, M., Baccari, C., Da Silva, A. M., Garcia, A., Yokota, K., and Lindow, S. E. 2013. Diffusible signal factor (DSF) synthase RpfF of Xylella fastidiosa is a multifunction protein also required for response to DSF. J. Bacteriol. 195:5273-5284.

Ionescu, M., Yokota, K., Antonova, E., Garcia, A., Beaulieu, E., Hayes, T., Iavarone, A. T., and Lindow, S. E. 2016. Promiscuous diffusible signal factor production and responsiveness of the Xylella fastidiosa Rpf system. MBio 7:e01054.

King, E. O., Ward, M. K., and Raney, D. E. 1954. Two simple media for the demonstration of pyocyanin and fluorescin. J. Lab. Clin. Med. 44:301-307.

Lacava, P. T., Araujo, W. L., Marcon, J., Maccheroni, W., Jr., and Azevedo, J. L. 2004. Interaction between endophytic bacteria from citrus plants and the phytopathogenic bacteria Xylella fastidiosa, causal agent of citrusvariegated chlorosis. Lett. Appl. Microbiol. 39:55-59.

Lacava, P. T., Li, W., Araujo, W. L., Azevedo, J. L., and Hartung, J. S. 2007. The endophyte Curtobacterium flaccumfaciens reduces symptoms caused by Xylella fastidiosa in Catharanthus roseus. J. Microbiol. 45:388-393.

Ledger, T., Rojas, S., Timmermann, T., Pinedo, I., Poupin, M. J., Garrido, T., Richter, P., Tamayo, J., and Donoso, R. 2016. Volatile-mediated effects predominate in Paraburkholderia phytofirmans growth promotion and salt stress tolerance of Arabidopsis thaliana. Front. Microbiol. 7:1838.

Lindow, S., Newman, K., Chatterjee, S., Baccari, C., Lavarone, A. T., and Ionescu, M. 2014. Production of Xylella fastidiosa diffusible signal factor in transgenic grape causes pathogen confusion and reduction in severity of Pierce's disease. Mol. Plant-Microbe Interact. 27:244-254.

Miotto-Vilanova, L., Jacquard, C., Courteaux, B., Wortham, L., Michel, J., Clement, C., Barka, E. A., and Sanchez, L. 2016. Burkholderia phytofirmans PsJN confers grapevine resistance against Botrytis cinerea via a direct antimicrobial effect combined with a better resource mobilization. Front. Plant Sci. 7:1236.

Mitter, B., Petric, A., Shin, M. W., Chain, P. S. G., Hauberg-Lotte, L., Reinhold-Hurek, B., Nowak, J., and Sessitsch, A. 2013. Comparative genome analysis of Burkholderia phytofirmans PsJN reveals a wide spectrum of endophytic lifestyles based on interaction strategies with host plants. Front. Plant Sci. 4:120.

Nascimento, R., Gouran, H., Chakraborty, S., Gillespie, H. W., Almeida-Souza, H. O., Tu, A., Rao, B. J., Feldstein, P. A., Bruening, G., Goulart, L. R., and Dandekar, A. M. 2016. The type II secreted lipase/ esterase LesA is a key virulence factor required for Xylella fastidiosa pathogenesis in grapevines. Sci. Rep. 6:21575.

Newman, K. L., Almeida, R. P. P., Purcell, A. H., and Lindow, S. E. 2003. Use of a green fluorescent strain for analysis of Xylella fastidiosa colonization of Vitis vinifera. Appl. Environ. Microbiol. 69:7319-7327.

Newman, K. L., Almeida, R. P. P., Purcell, A. H., and Lindow, S. E. 2004. Cell-cell signaling controls Xylella fastidiosa interactions with both insects and plants. Proc. Natl. Acad. Sci. USA 101:1737-1742.

Perez-Donoso, A. G., Greve, L. C., Walton, J. H., Shackel, K. A., and Labavitch, J. M. 2007. Xylella fastidiosa infection and ethylene exposure result in xylem and water movement disruption in grapevine shoots. Plant Physiol. 143:1024-1036.

Pieterse, C. M. J., Zamioudis, C., Berendsen, R. L., Weller, D. M., Van Wees, S. C. M., and Bakker, P. A. H. M. 2014. Induced systemic resistance by beneficial microbes. Annu. Rev. Phytopathol. 52:347-375.
Pillay, V. K., and Nowak, J. 1997. Inoculum density, temperature, and genotype effects on in vitro growth promotion and epiphytic and endophytic colonization of tomato (Lycopersicon esculentum L.) seedlings inoculated with a pseudomonad bacterium. Can. J. Microbiol. 43:354-361.

Rapicavoli, J. N., Blanco-Ulate, B., Muszynski, A., Figueroa-Balderas, R., Morales-Cruz, A., Azadi, P., Dobruchowska, J. M., Castro, C., Cantu, D., and Roper, M. C. 2018. Lipopolysaccharide O-antigen delays plant innate immune recognition of Xylella fastidiosa. Nat. Commun. 9:390.

Saponari, M., Boscia, D., Altamura, G., Loconsole, G., Zicca, S., D'Attoma, G., Morelli, M., Palmisano, F., Saponari, A., Tavano, D., Savino, V. N., Dongiovanni, C., and Martelli, G. P. 2017. Isolation and pathogenicity of Xylella fastidiosa associated to the olive quick decline syndrome in southern Italy. Sci. Rep. 7:17723.

Saponari, M., Loconsole, G., Cornara, D., Yokomi, R. K., De Stradis, A., Boscia, D., Bosco, D., Martelli, G. P., Krugner, R., and Porcelli, F. 2014. Infectivity and transmission of Xylella fastidiosa by Philaenus spumarius (Hemiptera: Aphrophoridae) in Apulia, Italy. J. Econ. Entomol. 107: 1316-1319.

Sawana, A., Adeolu, M., and Gupta, R. S. 2014. Molecular signatures and phylogenomic analysis of the genus Burkholderia: Proposal for division of this genus into the emended genus Burkholderia containing pathogenic organisms and a new genus Paraburkholderia gen. nov harboring environmental species. Front. Genet. 5:429.

Sessitsch, A., Coenye, T., Sturz, A. V., Vandamme, P., Barka, E. A., Salles, J. F., Van Elsas, J. D., Faure, D., Reiter, B., Glick, B. R., Wang-Pruski, G., and Nowak, J. 2005. Burkholderia phytofirmans sp. nov., a novel plantassociated bacterium with plant-beneficial properties. Int. J. Syst. Evol. Microbiol. 55:1187-1192.

Sharma, V. K., and Nowak, J. 1998. Enhancement of Verticillium wilt resistance in tomato transplants by in vitro co-culture of seedlings with a plant growth promoting rhizobacterium (Pseudomonas sp. strain PsJN). Can. J. Microbiol. 44:528-536.

Sicard, A., Zeilinger, A. R., Vanhove, M., Schartel, T. E., Beal, D. J., Daugherty, M. P., and Almeida, R. P. P. 2018. Xylella fastidiosa: Insights into an emerging pathogen. Annu. Rev. Phytopathol. 56:181-202.

Su, F., Gilard, F., Guerard, F., Citerne, S., Clement, C., Vaillant-Gaveau, N., and Dhondt-Cordelier, S. 2016. Spatio-temporal responses of Arabidopsis leaves in photosynthetic performance and metabolite contents to Burkholderia phytofirmans PsJN. Front. Plant Sci. 7:403.

Sun, Q., Sun, Y., Walker, M. A., and Labavitch, J. M. 2013. Vascular occlusions in grapevines with Pierce's disease make disease symptom development worse. Plant Physiol. 161:1529-1541.

Suppiger, A., Aguilar, C., and Eberl, L. 2016. Evidence for the widespread production of DSF family signal molecules by members of the genus Burkholderia by the aid of novel biosensors. Environ. Microbiol. Rep. 8: $38-44$.

Theocharis, A., Bordiec, S., Fernandez, O., Paquis, S., Dhondt-Cordelier, S., Baillieul, F., Clement, C., and Barka, E. A. 2012. Burkholderia phytofirmans PsJN primes Vitis vinifera $\mathrm{L}$. and confers a better tolerance to low nonfreezing temperatures. Mol. Plant-Microbe Interact. 25:241-249.

Timmermann, T., Armijo, G., Donoso, R., Seguel, A., Holuigue, L., and Gonzalez, B. 2017. Paraburkholderia phytofirmans PsJN protects Arabidopsis thaliana against a virulent strain of Pseudomonas syringae through the activation of induced resistance. Mol. Plant-Microbe Interact. 30:215-230.

Trda, L., Fernandez, O., Boutrot, F., Heloir, M.-C., Kelloniemi, J., Daire, X., Adrian, M., Clement, C., Zipfel, C., Dorey, S., and Poinssot, B. 2014. The grapevine flagellin receptor VvFLS2 differentially recognizes flagellinderived epitopes from the endophytic growth-promoting bacterium Burkholderia phytofirmans and plant pathogenic bacteria. New Phytol. 201: 1371-1384.

Wilhelm, M., and Kirkpatrick, B. C. 2007. Assessment of grapevine endophytic bacteria for control of Pierce's disease. Phytopathology 97:S123. 